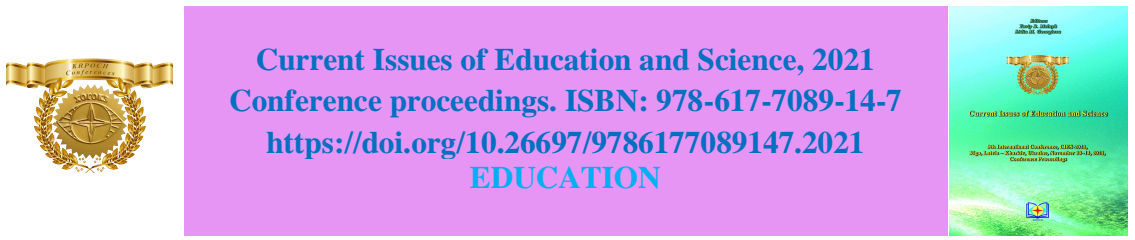

DOI: $\underline{\text { https://doi.org/10.26697/9786177089147.2021.04 }}$

\title{
Integration Technology in Math Lessons
}

Senad ORHANI ${ }^{1}$

${ }^{1}$ University of Prishtina, Prishtina

Corresponding Author Details

Senad ORHANI, senad.orhani@uni-pr.edu

Received: 15.10.2021; Accepted: 10.11.2021; Published: 17.12.2021

\section{Brief Summary}

Background: Teaching and learning in today's classrooms are transforming to meet the changing demands of the society. One of the biggest changes experienced by teachers and students is the introduction of technology-based tools to aid teaching and learning. Mathematics enables the development of students' skills and abilities to think critically, the development of their personality, the development of skills to work independently and systematically, the stimulation of curiosity and encouragement for discovery, the building of knowledge new in order to implement and integrate them in other areas and solve problem situations in everyday life.

The aim of the study: To present the effective experiences of integrating technological tools in the teaching and learning of concepts in lessons in the subject of mathematics

Methods: The empirical method was used for this study, with quantitative approach. The sample for this study is represented by the teachers and students of the lower secondary school, with 40 participants. Quantitative data were collected from the answers of the participants in the questionnaire.

Results: The findings of the study reflect the high scores of the participants regarding the integration of technology in math lessons, and that this is becoming more prominent in online learning perhaps even in the development of distance learning during the COVID-19 pandemic period. 
Conclusions: The information from the study can be used to support other teachers who are not yet integrating technology into the learning process. But it is important to note that technology is only a teaching tool. No form of technology in the subject of mathematics can ever replace a very effective teacher.

\section{Keywords:}

learning, math, students, teaching and technology.

\section{Background:}

The world is changing rapidly in parallel with science revolutions and the evolution of technology. The challenge of accelerating change in the field of education in the 21st century is to find and develop tools that can make teaching and learning effective and worthwhile. Technology has an impact and change in efficiency as a tool that can change the way the subject is taught in teaching practice, which facilitates the learning process as a tool for collecting, organizing and evaluating information in problem solving and to innovate practical ideas. in the reality of life.

As a result, the integration of technology in this study refers to the use of technology in the teaching process in the field of mathematics, which can contribute positively to the performance of students and teachers. Technology integration is also linked to a range of dynamic factors, including effective practices, technological aspects of new tools, the potential to transform learning, the development of online learning, the use of digital learning tools, and the enabling of new forms of practice of teaching and learning. The role of technology in mathematics is one of the key factors in motivating and engaging students for lessons. Technology helps develop learning activities by providing an interactive environment where students examine and visualize exercise presentations and dynamically relate to symbolic expressions, numerical and graphical data.

The application of new technology in the teaching and learning of mathematics is a reform of the 21st century. In this new reality it is necessary to seek new teaching methodologies and teachers need differentiated and sustainable educational tools with the reality in which students are facing. Schools need to keep pace with the times, harnessing the full potential of each student and thus improving the act of teaching and learning in step with technological advances. However, new technologies such as smart boards, computers and iPads have become part of educational systems and cannot now be ignored. 
Mathematics is a subject that requires a multifaceted approach and technology offers an opportunity for the student to learn mathematics in a variety of ways. The programs are convenient to use and this provides an opportunity to create a host of different representations within the school's limited daily time. Technology offers the opportunity to present a variety of representations and multiple opportunities to learn in different ways, ensuring that many students become active. These multiple representations can add depth to students' understanding of the concept, which is important as we have seen that students struggle with approaches because there is often an emphasis on a procedural meaning rather than a conceptual meaning (Mudaly \& Fletcher, 2019).

The use of technology, and especially mobile technologies, in the teaching and learning of mathematics is gaining increasing interest among researchers and practitioners (Borba et al., 2017). According to Zengin and Tatar (2017) technology within the classroom is not a tool to transfer knowledge, but rather a tool that offers students an opportunity to engage and build their knowledge.

Technology-based tools for the subject of mathematics include specific technology-based tools and technology-based tools for general purposes. Technologies based tools on specific I mathematics include mathematical software, web resources, and other web sites that focus on teaching and learning mathematics subjects. General purpose technologybased tools include productivity software, interactive whiteboards, and general software that suggest that in math classes both can be used to teach math effectively (Mlilo, 2019).

GeoGebra is a dynamic math software for teaching and learning math. You can use it for active and problem-oriented teaching, it encourages experiments and mathematical discoveries both in the classroom and at home. GeoGebra is used to visualize geometric objects that will be transformed. Through the process of visualization students try, reason and finally find the concept of transformation. Based on this, learning using GeoGebra software can improve math skills (Simbolon \& Siahaan, 2020).

Mathway is a popular app for students and teachers, as it not only helps students see the answers to difficult problems, but shows them the steps to find the answer. This can be especially helpful for students who are learning at home, for those who do not have access to a teacher, or even for adults who simply want to control their math (Tucker, 2020).

E-learning is a structured field or electronically provided learning experience, which is developed through electronic media, usually including the Internet. We distinguish two types of e-learning, that of synchronous and asynchronous e-learning. Synchronous e-learning, most often referred 
to as direct online training, online learning or virtual classroom training, which is led by teachers and takes place at the same time as other students, all occur to be geographically dispersed. Alternatively, asynchronous elearning may include pre-recorded lecture and video content, visuals and/or text, knowledge quizzes, simulations, games and other interactive elements (Bonderud, 2020).

Google Classroom as learning aids digital tools like Google Classroom, enable teachers to create and organize assignments, tests, provide feedback, and easily communicate with their virtual classrooms. Google Classroom is an online service developed by Google to support teaching and learning in virtual classrooms. Math teachers can create, distribute, and assign tasks to anyone within the group. Each class creates a separate folder in Google Drive of the respective user, where the student can submit the work to be evaluated by a teacher (Edwards, 2021).

Google Meet can empower you to enrich teaching and learning with advanced features like breakout rooms, live streaming, attendance tracking, Q\&A, polling and more when you sign up for the Teaching and Learning Upgrade. Google Meet is a video conferencing program from Google Suite to allow teachers to continue to meet the needs of their students through direct math instruction. Math teachers can share their screens to show visuals and model problem-solving strategies (Sapp, 2020).

M-learning has the potential to become an integral part of the teaching and learning processes in the subject of mathematics, which is increasingly common for students to use mobile technology. M-learning technologies include laptops, notebooks, smartphones and tablets. Mlearning focuses on student mobility, interacting with portable technologies. Using mobile tools to create teaching tools and materials that have become an important part of non-formal learning. Mobile learning has managed to increase the efficiency of e-learning by taking it one step further and allowing students to learn almost anywhere and anytime (Semertzidis, 2013).

Game Based Learning balances the subject with the game. The goal is to allow students to recall information gained from the game and apply it to real-world life situations. When applied with the right curriculum, gamebased learning can help them learn a subject more effectively. Game-based learning is where game features and principles are incorporated into learning activities. Here, learning activities foster student engagement and motivation to learn. Games work best when paired with effective pedagogy. As such, researchers suggest that games will not replace teachers and classrooms, but they may replace some textbooks and labs (Schenke et al., 2014). 
Mathematics is a basic skill in many aspects of a student's life. Most students sometimes lack motivation in math lessons. On the other hand, the impact on social life promoted by technology represents a unique opportunity for the development of the learning process, as it facilitates and provides meaningful learning through technological resources.

The aim of the study. To present the effective experiences of integrating technological tools in the teaching and learning of concepts in the lessons of mathematics.

\section{Methods:}

The empirical method was used for this study, to investigate how many teachers and students are integrating technological tools into the math lessons. The quantitative approach was used to analyze this study in more detail. The quantitative approach of this study aims to reveal trends regarding the frequency of use of technological tools in the teaching and learning process.

The sample for this study is represented by the teachers and students of the lower secondary school "Heronjtë e Lumës" from the village of Vërmica, municipality of Prizren. The selected sample is a non-probabilistic sample with 40 participants, which was a deliberate sample, due to the evaluation of the use of technology in the learning process.

Quantitative data were collected from the answers of the participants in the questionnaire. Questionnaires were compiled on the Likert scale, which were measuring instruments that reflected quantitative data. Participants' responses were assessed for ideas, values, opinions or attitudes whether they agree or disagree with the statements made. Quantitative data collected from the questionnaire were then analyzed through the SPSS program, where the data collected from the questionnaires were transcribed, categorized and finally interpreted.

\section{Results:}

Quantitative data obtained from the questionnaires show a comprehensive understanding of participants' attitudes regarding the integration of technology in mathematics lessons. This study included 40 participants, of whom 37 were students and 3 teachers from primary and lower secondary schools in this country.

According to the results, one third of teachers had knowledge of low level of technology use, while two thirds had high level of technology use. Based on this, the research results show that about $66.7 \%$ of teachers are in favor of integrating technology in math lessons, while $33.3 \%$ are reluctant to integrate technology in the teaching process. Also, the results of the teachers show that all participants use the GeoGebra program and online 
learning (e-learning), 33.3\% of the application Mathway, m-learning and Game Based Learning, as well as $66.7 \%$ of participants use the Google Classroom and Google Meet platforms.

On the other hand, the study results show that about $29.7 \%$ of students had low level knowledge of technology use, $43.2 \%$ medium level knowledge, and $27.1 \%$ had high level knowledge of technology use. Also, in terms of integration of technology in mathematics learning, the results show that $43.2 \%$ use the GeoGebra program, $13.5 \%$ use the Mathway application, $100 \%$ are involved in online learning, $67.6 \%$ use the Google Classroom platform, 59.5\% use the Google Meet platform, $18.9 \%$ mobile learning (m-learning) and only $13.5 \%$ of students had integrated digital games into mathematics learning.

Therefore, from the results of the research we see that almost all participants have integrated some form of technology in the teaching process of the subject of mathematics. The findings of the study reflect the high scores of the participants regarding the integration of technology in math lessons, and that this is becoming more prominent in online learning perhaps even in the development of distance learning during the COVID-19 pandemic period. Furthermore, we consider the possibility of incorporating technology into math lessons, where technology can improve the teaching and learning process.

\section{Conclusions:}

It was important to identify the technology-based tools currently used in math classes in order to exchange information with teachers for planning purposes. Information from the study can be used to support other teachers who are not yet integrating technology into the learning process. Furthermore, it will help students become more involved in their learning and take an active part in their education. But it is important to note that technology is only a teaching tool. No form of technology in the subject of mathematics can ever replace a very effective teacher. The bottom line is that effective teaching is about engaging students in order to help students develop a deeper understanding of mathematical concepts. Effective math teachers use technology as a tool to support engagement and learning, but not as an end in itself. Regarding curriculum issues, it is necessary to develop and apply teaching and learning methodologies to master the resources made available by technology, in order to use them as auxiliary resources to support the understanding of mathematical concepts and motivation students in the classroom.

\section{Conflicts of interests:}

The author declares that there is no conflict of interests. 


\section{Source of support:}

This research did not receive any outside funding or support.

\section{References}

Bonderud, D. (2020, February 27). How e-learning supports on-demand instruction for $K-12$ schools. EdTech. https://edtechmagazine.com/k12/article/2020/02/how-e-learningsupports-demand-instruction-k-12-schools-perfcon

Borba, M., Askar, P., Engelbrecht, J., Gadanidi, G., Llinares, S., \& Aguila, M. (2017). Digital technology in mathematics education: Research over the last decade. In G. Kaiser (Ed.), Proceedings of the 13th International Congress on Mathematical Education (pp. 221-233). Springer. https://doi.org/10.1007/978-3-319-62597-3_14

Edwards, L. (2021, March 19). What is Google Classroom? Teach \& Learning. https://www.techlearning.com/features/what-is-googleclassroom

Mlilo, T. (2019). Exploring the integration of technology - based tools in intermediate mathematics classrooms [Master's thesis]. University of

KwaZulu-Natal. https://researchspace.ukzn.ac.za/xmlui/bitstream/handle/10413/1913 3/Mlilo_Thobekile_2019.pdf?sequence $=1$ \&isAllowed $=\mathrm{y}$

Mudaly, V., \& Fletcher, T. (2019). The effectiveness of GeoGebra when teaching linear functions using the iPad. Problems of Education in the 21st Century, 77(1), 55-81. https://doi.org/10.33225/pec/19.77.55

Sapp, T. (2020). Using Google classroom to teach mathematics in grades 3 5. Middle Georgia State University. https://www.gctm.org/resources/Reflections/issues/winter2021/PDFs W21/6_Tyler_Sapp_Using\%20Google\%20Classroom\%20to\%20teac h\%20Mathematics\%20in\%20Grade\%203-5.pdf

Schenke, K., Rutherford, T., \& Farkas, G. (2014). Alignment of game design features and state mathematics standards: Do results reflect intentions? Computers \& Education, 76(July), 215-224. https://doi.org/10.1016/j.compedu.2014.03.019

Semertzidis, K. (2013). Mobile application development to enhance higher education lectures [Master's thesis]. The University of York. https://www.cs.uoi.gr/ ksemer/docs/theses/msc-ksemer.pdf

Simbolon, A., \& Siahaan, L. M. (2020). The use of GeoGebra software in improving student's mathematical abilities in learning geometry. In A. Turnip (Ed.), International Conference on Culture Heritage, 
Education, Sustainable Tourism, and Innovation Technologies (pp. 352-360). https://doi.org/10.5220/0010311803520360

Tucker, J. (2020, July 17). What the tech? App of the day - Mathway. Nexstar Media Inc. https://www.texomashomepage.com/news/localnews/what-the-tech-app-of-the-day-mathway/

Zengin, Y., \& Tatar, E. (2017). Integrating dynamic mathematics software into cooperative learning environments in mathematics. Journal of Educational Technology \& Society, 20(2), 74-88. https://www.jstor.org/stable/90002165

\section{Information about the author:}

Orhani Senad - https://orcid.org/0000-0003-3965-0791; Graduate Student, University of Prishtina, Prishtina.

Research interests: education, math.

\section{Cite this article as:}

Orhani, S. (2021). Integration technology in math lessons. In Yu. B. Melnyk, \& L. M. Georgieva (Eds.), Current Issues of Education and Science. 9th International Conference, CIES-2021, Riga, Latvia - Kharkiv, Ukraine, November 10-13, 2021, Conference proceedings (pp. 25-32). KRPOCH. https://doi.org/10.26697/9786177089147.2021.04

\section{Copyright information:}
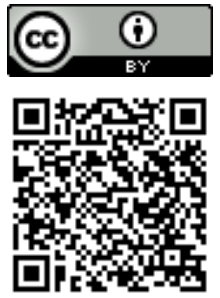

The published paper are licensed under a Creative Commons "Attribution" 4.0 Worldwide

The electronic version of this article is complete. Full or partial reproduction of article is allowed, citing to the source, author(s) and DOI. An electronic copy of the Conference proceedings in open access is available via the KRPOCH Publishing website https://publisher.culturehealth.org 